\title{
Selecting the Best of Portfolio Using OWA Operator Weights in Cross Efficiency-Evaluation
}

\author{
Masoud Sanei ${ }^{1}$ and Shokoofeh Banihashemi ${ }^{2}$ \\ ${ }^{1}$ Department of Applied Mathematics, Islamic Azad University, Central Tehran Branch, Tehran, Iran \\ ${ }^{2}$ Department of Mathematics, Computer and Statistics, Faculty of Economics, Allameh Tabataba'i University, Central Tehran Branch, \\ Tehran, Iran
}

Correspondence should be addressed to Shokoofeh Banihashemi; shbanihashemi@atu.ac.ir

Received 9 December 2013; Accepted 15 January 2014; Published 19 March 2014

Academic Editors: C. Join and F. Sartoretto

Copyright (c) 2014 M. Sanei and S. Banihashemi. This is an open access article distributed under the Creative Commons Attribution License, which permits unrestricted use, distribution, and reproduction in any medium, provided the original work is properly cited.

The present study is an attempt toward evaluating the performance of portfolios and asset selection using cross-efficiency evaluation. Cross-efficiency evaluation is an effective way of ranking decision making units (DMUs) in data envelopment analysis (DEA). The most widely used approach is to evaluate the efficiencies in each row or column in the cross-efficiency matrix with equal weights into an average cross-efficiency score for each DMU and consider it as the overall performance measurement of the DMU. This paper focuses on the evaluation process of the efficiencies in the cross-efficiency matrix and proposes the use of ordered weighted averaging (OWA) operator weights for cross-efficiency evaluation. The OWA operator weights are generated by the minimax disparity approach and allow the decision maker (DM) or investor to select the best assets that are characterized by an orness degree. The problem consists of choosing an optimal set of assets in order to minimize the risk and maximize return. This method is illustrated by application in mutual funds and weights are obtained via OWA operator for making the best portfolio. The finding could be used for constructing the best portfolio in stock companies, in various finance organization, and public and private sector companies.

\section{Introduction}

In financial literature, a portfolio is an appropriate mix of investments held by an institution or private individuals. Evaluation of portfolio performance has created a large interest among employees also academic researchers because of huge amount of money being invested in financial markets. The theory of mean-variance, Markowitz [1] is considered the basis of many current models and this theory is widely used to select portfolios. This model is due to the nature of the variance in quadratic form. Other problem in Markowitz model is that increasing the number of assets will develop the covariance matrix of asset returns and will be added to the content calculation. Due to these problems sharp one-factor model is proposed by Sharpe [2]. This method reduces the number of calculations requiring information for the decision. Data envelopment analysis (DEA) has proved the efficiency for assessing the relative efficiency of decision making units (DMUs) employing multiple inputs to produce multiple outputs [3]. M. R. Morey and R. C. Morey [4] proposed mean-variance framework based on Data Envelopment Analysis, which the variance of the portfolios is used as an input to the DEA and expected return is the output. Joro and $\mathrm{Na}$ [5] introduced meanvariance-skewness framework and skewness of returns are also considered as an output. The portfolio optimization problem is a well-known problem in financial real world. The investor's objective is to get the maximum possible return on an investment with the minimum possible risk. Since there are a large number of assets to invest in, this objective leads to select the best assets via cross-efficiency matrix by using OWA weighted. Cross-efficiency evaluation, proposed by Sexton et al., [6] is the effective way of ranking decision making units (DMUs). It allows the overall efficiencies of the DMUs to be evaluated through self- and peer-evaluations. The self-evaluation allows the efficiencies of the DMUs to 
be evaluated with the most favorable weights so that each of them can achieve its best possible relative efficiency, whereas the peer-evaluation requires the efficiency of each DMU to be evaluated with the weights determined by the other DMUs. The self-evaluated efficiency and peer-evaluated efficiencies of each DMU are then averaged as the overall efficiency of the DMU. Since, its remarkable discrimination power, the cross-efficiency evaluation has found significant number of applications in a wide variety of areas such as preference voting and project ranking $[7,8]$, economicenvironmental performance assessment $[9,10]$, and Olympic ranking and benchmarking [11-13]. Besides a large number of applications, theoretical research has also been conducted on the cross-efficiency evaluation. For example, Doyle and Green [14, 15] presented mathematical formulations for possible implementations of aggressive and benevolent crossefficiencies. Liang et al. [16] suggested the concept of game cross-efficiency and developed a game cross-efficiency model which treats each DMU as a player that seeks to maximize own efficiency under the condition that the cross-efficiency of each of the other DMUs dose not deteriorate. Wu et al. [13] extended the game cross-efficiency model to variable returns to scale later. In our work, the use of equal weights for cross-efficiency model has a significant problem. That is, self-evaluated efficiencies are much less weighted than peer-evaluated efficiencies. This is because each DMU has only one self-evaluated efficiency value, but multiple peerevaluated efficiency values. When they are simply averaged together, the weight assigned to the self-evaluated efficiency is only $1 / n$ if there are $n$ DMUs to be evaluated, whereas the remaining weights $(n-1) / n$ are all given to those peerevaluated efficiencies. To overcome this problem, the use of ordered weighted averaging (OWA) operator weights is stated for assets cross-efficiencies. The use of OWA operator weights for the assets cross-efficiency allows the weights to be reasonably allocated between self- and peer-evaluated efficiencies by investor's control [17]. The OWA operator weights are generated by the minimax disparity approach and allow the decision maker (DM) or investors to select the best assets that are characterized by an orness degree [18]. The method consists of choosing an optimal set of assets in order to minimize the risk and maximize return in cross-efficiency using OWA operator. Since there are a large number of assets to invest in, the best assets are chosen via crossefficiency evaluation by using OWA weighted by control investors.

The rest of the paper is organized as follows: Section 2 briefly reviews the portfolio performance literature, OWA operators, and their weight determination methods, thus the cross-efficiency evaluation in DEA. Section 3 develops a proposed method for selecting the best of the portfolio. Section 4 presents computational results using mutual funds data and finally conclusions are given in Section 5 .

\section{Background}

2.1. Portfolio Performance Literature. Portfolio theory to investing is published by Markowitz (1952). This approach starts by assuming that an investor has a given sum of money to invest at the present time. This money will be invested for a time as the investor's holding period. At the end of the holding period, the investor will sell all of the assets that were bought at the beginning of the period and then either consume or reinvest. Since portfolio is a collection of assets, it is better to select an optimal portfolio from a set of possible portfolios. Hence, the investor should recognize the returns (and portfolio returns), expected (mean) return, and standard deviation of return. This means that the investor wants to both maximize expected return and minimize uncertainty (risk). Rate of return (or simply the return) of the investor's wealth from the beginning to the end of the period is calculated as follows:

\section{Return

$$
=\frac{(\text { end-of-period wealth })-(\text { beginning-of-period wealth })}{\text { beginning-of-period wealth }} .
$$

Since Portfolio is a collection of assets, its return $r_{p}$ can be calculated in a similar manner. Thus, according to Markowitz, the investor should view the rate of return associated with any one of these portfolios as what is called in statistics a random variable. These variables can be described as the expected return $\left(\min\right.$ or $\left.\bar{r}_{p}\right)$ and standard deviation of return. Expected return and deviation standard of return are calculated as follows:

$$
\bar{r}_{p}=\sum_{i=1}^{n} \lambda_{i} \bar{r}_{i}, \quad \sigma_{p}=\left[\sum_{i=1}^{n} \sum_{j=1}^{n} \lambda_{i} \lambda_{j} \sigma_{i j}\right]^{1 / 2},
$$

where $n$ is the number of assets in the portfolio, $\bar{r}_{p}$ is the expected return of the portfolio, $\lambda_{i}$ is the proportion of the portfolio's initial value invested in asset $i, \bar{r}_{i}$ is the expected return of asset $i, \sigma_{p}$ is the deviation standard of the portfolio, and $\sigma_{i j}$ is the covariance of the returns between asset $i$ and asset $j$.

In the above, optimal portfolio from the set of portfolios will be chosen as maximum expected return for varying levels of risk and minimum risk for varying levels of expected return [19]. Data Envelopment Analysis is a nonparametric method for evaluating the efficiency of systems with multiple inputs and multiple outputs. In this section, we present some basic definitions, models, and concepts that will be used in other sections in DEA. They will not be discussed in details. Consider $\mathrm{DMU}_{j},(j=1, \ldots, n)$, where each DMU consumes $m$ inputs to produce $s$ outputs. Suppose that the observed input and output vectors of $\mathrm{DMU}_{j}$ are $X_{j}=\left(x_{1 j}, \ldots, x_{m j}\right)$ and $Y_{j}=\left(y_{1 j}, \ldots, y_{s j}\right)$, respectively, and let $X_{j} \geq 0$ and 
$X_{j} \neq 0, Y_{j} \geq 0$, and $Y_{j} \neq 0$. A basic DEA formulation in input orientation is as follows:

$$
\begin{array}{ll}
\min & \theta-\varepsilon\left(\sum_{r=1}^{s} s_{r}^{+}+\sum_{i=1}^{m} s_{i}^{-}\right) \\
\text {s.t. } & \sum_{j=1}^{n} \lambda_{j} x_{i j}+s_{i}^{-}=\theta x_{i o} \quad i=1, \ldots, m, \\
& \sum_{j=1}^{n} \lambda_{j} y_{r j}+s_{r}^{+}=y_{r o} \quad r=1, \ldots, s \\
& \lambda \in \Lambda, \\
& s^{+}, s^{-} \geq 0 \\
& \varepsilon \geq 0
\end{array}
$$

where $\lambda$ is an $n$-vector of $\lambda$ variables, $s^{+}$as-vector of output slacks, $s^{-}$an $m$-vector of input slacks and set $\Lambda$ is defined as follows:

$$
\Lambda= \begin{cases}\left\{\lambda \in R_{+}^{n}\right\} & \text { with constant returns to scale, } \\ \left\{\lambda \in R_{+}^{n}, 1 \lambda \leq 1\right\} & \text { with nonincreasing } \\ \left\{\lambda \in R_{+}^{n}, 1 \lambda=1\right\} & \text { returns to scale, } \\ \text { with variable returns to scale. }\end{cases}
$$

Note that subscript " $o$ " refers to the unit under the evaluation. A DMU is efficient if and only if $\theta=1$ and all slack variables $s^{-}, s^{+}$equal zero; otherwise, it is inefficient [20]. In the DEA formulation above, the left-hand sides in the constraints define an efficient portfolio. $\theta$ is a multiplier which defines the distance from the efficient frontier. The slack variables are used to ensure that the efficient point is fully efficient. This model is used for asset selection. The portfolio performance evaluation literature is vast. In recent years, these models have been used to evaluate the portfolio efficiency. Also, in the Markowitz theory, it is required to characterize the whole efficient frontier but the proposed models by Joro and $\mathrm{Na}$ do not need to characterize the whole efficient frontier but only the projection points. The distance between the asset and its projection which means the ratio between the variance of the projection point and the variance of the asset is considered as an efficiency measure $(\theta)[5]$.

2.2. OWA Operators and Their Weight Determination Methods. An OWA operator of dimension $n$ is a mapping $F$ : $\mathfrak{R}^{n} \rightarrow \mathfrak{R}$ with an associated weight vector $W=$ $\left(w_{1}, \ldots, w_{n}\right)^{T}$ such that

$$
\begin{gathered}
w_{1}+\cdots+w_{n}=1, \quad o \leq w_{i} \leq 1, \quad i=1, \ldots, n, \\
F\left(a_{1}, \ldots, a_{n}\right)=\sum_{i=1}^{n} w_{i} b_{i},
\end{gathered}
$$

where $b_{i}$ is the $i$ th largest of $a_{1}, \ldots, a_{n}$.

OWA operators, introduced by Yager [21], provide a unified framework for decision making under uncertainty, where different decision criteria such as maximax (optimistic), maximin (pessimistic), and equally likely (Laplace), and Hurwicz criteria are characterized by different OWA operator weights.

For different weight selections, they are distinguished by the following orness degree [21]:

$$
\text { orness }(W)=\frac{1}{n-1} \sum_{i=1}^{n}(n-i) w_{i} \text {. }
$$

The orness degree can be regarded as a measure of the optimism level of the DM.

To apply OWA operators for decision making, it is essential to determine the weights of OWA operators. The following models (7) and (8) are two important approaches for determining OWA operator weights under a given orness degree:

$$
\begin{aligned}
& \text { Maximize } \operatorname{Disp}(W)=-\sum_{i=1}^{n} w_{i} \ln w_{i} \\
& \text { Subject to orness }(W)=\alpha=\frac{1}{n-1} \sum_{i=1}^{n}(n-i) w_{i}, \\
& \qquad 0 \leq \alpha \leq 1,
\end{aligned}
$$

$$
\begin{aligned}
& \sum_{i=1}^{n} w_{i}=1, \\
& w_{i} \geq 0, \quad i=1, \ldots, n,
\end{aligned}
$$

Minimize $\delta$

$$
\begin{aligned}
& \text { Subject to orness }(W)=\alpha=\frac{1}{n-1} \sum_{i=1}^{n}(n-i) w_{i}, \\
& \qquad \quad 0 \leq \alpha \leq 1, \\
& \sum_{i=1}^{n} w_{i}=1, \\
& w_{i}-w_{i+1}-\delta \leq 0, \quad i=1, \ldots, n-1, \\
& w_{i}-w_{i+1}-\delta \geq 0, \quad i=1, \ldots, n-1, \\
& w_{i} \geq 0, \quad i=1, \ldots, n .
\end{aligned}
$$

Model (7), suggested by O'Hagan [22], maximizes the entropy of weight distribution and is thus referred to as the maximum entropy method, whereas model (8) that was proposed by Wang and Parkan [18] minimizes the maximum disparity between two adjacent weights and is thus called the minimax disparity approach.

The OWA operator weights determined by the above models have the following characteristics.

The weights are ordered. That is, $w_{1} \geq w_{2} \geq \cdots \geq w_{n} \geq 0$ if the orness degree $\alpha>0.5$ and $0 \leq w_{1} \leq w_{2} \leq \cdots \leq w_{n}$ if $\alpha \leq 0.5$. 
The weights have nothing to do with the magnitudes of the aggregates $b_{1} \sim b_{n}$ but depend upon their ranking orders and the DM's optimism level (orness degree).

Consider $w_{1}=1$ and $w_{j}=0(j=1)$ if $\alpha=1$, which means that the DM or investor is purely optimistic and considers only the biggest value $b_{1}=\max _{i}\left(a_{i}\right)$ in decision analysis.

Consider $w_{n}=1$ and $w_{j}=0(j \neq n)$ if $\alpha=0$, which represents that the DM or investor is purely pessimistic and is only concerned with the most conservative value $b_{n}=$ $\min _{i}\left(a_{i}\right)$ when making decision.

Consider $w_{1}=\cdots=w_{n}=(1 / n)$ if $\alpha=0.5$, which stands for that the DM or investor is neutral and makes use of all the aggregates $b_{1} \sim b_{n}$ equally in decision making.

Consider $w_{1}, \ldots, w_{n}$ determined by model (7) vary in the form of geometric progression, that is $w_{i+1} / w_{i} \equiv q$ for $i=1, \ldots, n-1$, where $q>0$, while $w_{1}, \ldots, w_{n}$ determined by model (8) vary in the form of arithmetical progression; namely, $w_{i}-w_{i+1}=d$ for $i=1, \ldots, K(K \leq n)$ or $w_{i+1}-w_{i}=d$ for $i=K, \ldots, n(K \geq 1)$, where $d>0$.

2.3. The Cross-Efficiency Evaluation. Consider $n$ DMUs that are to be evaluated with $m$ inputs and $s$ output. Denote by $x_{i j}(1, \ldots, m)$ and $y_{r j}(r=1, \ldots, s)$ the input and output values of $\mathrm{DMU}_{j}(j=1, \ldots, n)$. The efficiencies of the $n$ DMUs can then be computed by solving the following CCR model for each of the $n$ DMUs, respectively [3]:

$$
\begin{array}{ll}
\max & \theta_{k k}=\sum_{r=1}^{s} u_{r k} y_{r k}, \\
\text { subject to } \quad & \sum_{i=1}^{m} v_{i k} x_{i k}=1, \\
& \sum_{r=1}^{s} u_{r k} y_{r j}-\sum_{r=1}^{s} v_{i k} x_{i j} \leq 0, \quad j=1, \ldots, n, \\
& u_{r k}, v_{i k} \geq 0, \quad r=1, \ldots, s, i=1, \ldots, m,
\end{array}
$$

where $\mathrm{DMU}_{k}$ is the $\mathrm{DMU}$ under evaluation and $v_{i k}(i=$ $1, \ldots, m)$ and $u_{r k}(r=1, \ldots, s)$ are input and output weights. Let $u_{r k}^{*}(r=1, \ldots, s)$ and $v_{i k}^{*}(i=1, \ldots, m)$ be the optimal solution to the above CCR model. Then, $\theta_{k k}^{*}=\sum_{r=1}^{s} u_{r k}^{*} y_{r k}$ is referred to as the CCR-efficiency of $\mathrm{DMU}_{k}$, which is the best relative efficiency of $\mathrm{DMU}_{k}$ by self-evaluation. If $\theta_{k k}^{*}=$ $1, \mathrm{DMU}_{k}$ is said to be CCR-efficient; otherwise, it is said to be non-CCR-efficient. $\theta_{j k}=\sum_{r=1}^{s} u_{r k}^{*} y_{r j} / \sum_{i=1}^{m} v_{i k}^{*} x_{i j}$ is referred to as the cross-efficiency of $\mathrm{DMU}_{k}$ to $\mathrm{DMU}_{j}$ by peerevaluation; where $j=1, \ldots, n ; j \neq k$.

Model (9) is solved $n$ times, each time for one particular DMU. As a result, we can get one CCR-efficiency value and $(n-1)$ cross-efficiency values for each DMU. The $n$ efficiency values constitute a cross-efficiency matrix, as shown in Table 1 , where $\theta_{k k}(k=1, \ldots, n)$ are the CCRefficiency values of the $n$ DMUs; that is, $\theta_{k k}=\theta_{k k}^{*}$. The $n$ efficiency values of each DMU are then simply averaged as its overall performance, which is called average cross-

\begin{tabular}{|c|c|c|c|c|c|}
\hline \multirow{2}{*}{ DMU } & \multicolumn{4}{|c|}{ Target DMU } & \multirow{2}{*}{ Average crosses efficiency } \\
\hline & 1 & 2 & $\cdots$ & $n$ & \\
\hline 1 & $\theta_{11}$ & $\theta_{12}$ & $\cdots$ & $\theta_{1 n}$ & $\left(\frac{1}{n}\right) \sum_{k=1}^{n} \theta_{1 k}$ \\
\hline 2 & $\theta_{21}$ & $\theta_{22}$ & $\cdots$ & $\theta_{2 n}$ & $\left(\frac{1}{n}\right) \sum_{k=1}^{n} \theta_{2 k}$ \\
\hline : & $\vdots$ & $\vdots$ & & $\vdots$ & : \\
\hline$n$ & $\theta_{n 1}$ & $\theta_{n 2}$ & $\cdots$ & $\theta_{n n}$ & $\left(\frac{1}{n}\right) \sum_{k=1}^{n} \theta_{n k}$ \\
\hline
\end{tabular}
efficiency value. Based on these overall performance values, the $n$ DMUs can be compared or fully ranked.

\begin{tabular}{|c|c|c|c|c|c|}
\hline \multirow{3}{*}{ DMU } & \multicolumn{4}{|c|}{$\begin{array}{l}\text { Re-ordered efficiencies } \\
\text { in descending order }\end{array}$} & \multirow{3}{*}{$\begin{array}{l}\text { Weighted } \\
\text { average } \\
\text { cross } \\
\text { efficiency }\end{array}$} \\
\hline & 1st & 2nd & $\ldots$ & $n$th & \\
\hline & $w_{1}$ & $w_{2}$ & $\ldots$ & $w_{n}$ & \\
\hline 1 & $\vartheta_{11}$ & $\vartheta_{12}$ & $\ldots$ & $\vartheta_{1 n}$ & $\sum_{k=1}^{n} w_{k} \vartheta_{1 k}$ \\
\hline 2 & $\vartheta_{21}$ & $\vartheta_{22}$ & $\ldots$ & $\vartheta_{2 n}$ & $\sum_{k=1}^{n} w_{k} \vartheta_{2 k}$ \\
\hline$\vdots$ & $\vdots$ & $\vdots$ & & $\vdots$ & $\vdots$ \\
\hline$n$ & $\vartheta_{n 1}$ & $\vartheta_{n 2}$ & $\ldots$ & $\vartheta_{n n}$ & $\sum_{k=1}^{n} w_{k} \vartheta_{n k}$ \\
\hline
\end{tabular}

TABLE 1: Cross-efficiency matrix for $n$ DMUs.

TABLE 2: Re-ordered cross-efficiency matrix of the $n$ DMUs.

The above approach about cross-efficiency value in CCR efficiencies or constant returns to scale (CRS) DEA model was extended to the variable returns to scale (VRS) DEA model [13]. The VRS DEA model can generate negative crossefficiency scores.

The VRS DEA model is as follows [23]:

$$
\begin{array}{ll}
\max & \sum_{r=1}^{s} u_{r k} y_{r k}-u_{0} \\
\text { s.t. } \quad & \sum_{r=1}^{s} u_{r k} y_{r j}-\sum_{i=1}^{m} v_{i k} x_{i j}-u_{0} \leq 0, \quad j=1, \ldots, n \\
& \sum_{i=1}^{m} v_{i k} x_{i k}=1 \\
& u_{r k} \geq 0, \quad r=1, \ldots, s \\
& v_{i k} \geq 0, \quad i=1, \ldots, m \\
& u_{0} \geq 0 .
\end{array}
$$

For each $\mathrm{DMU}_{k}(k=1, \ldots, n)$ under evaluation in model (10), we obtain a set of optimal weights $\left(u_{r k}^{*}, v_{r k}^{*}\right)$. Using this set of weights, the $\mathrm{DMU}_{k}$-based cross-efficiency for any $\mathrm{DMU}_{j}(j=1, \ldots, n)$ is calculated as

$$
\begin{gathered}
E_{k j}=\frac{\sum_{r=1}^{s} u_{r k}^{*} y_{r j}-u_{0}}{\sum_{i=1}^{m} v_{i k}^{*} x_{i j}} \\
k, j=1,2, \ldots, n .
\end{gathered}
$$


TABLE 3: Descriptive statistics of the mutual funds.

\begin{tabular}{|c|c|c|}
\hline Mutual fund & Expected return & Variance \\
\hline ACEFX & 2.671 & 64.173 \\
\hline ACEGX & 2.734 & 64.254 \\
\hline ACEMX & 2.668 & 64.098 \\
\hline AELAX & 1.241 & 22.976 \\
\hline AELGX & 1.287 & 22.970 \\
\hline AGTHX & 1.902 & 23.445 \\
\hline ARCGX & 2.017 & 30.697 \\
\hline AVLFX & 1.615 & 19.817 \\
\hline BJBIX & 1.506 & 33.203 \\
\hline CUCAX & 1.990 & 24.858 \\
\hline FAGIX & 0.533 & 5.471 \\
\hline FAIAX & 1.404 & 39.099 \\
\hline FAICX & 1.420 & 39.095 \\
\hline FDEGX & 2.445 & 53.059 \\
\hline FEURX & 1.696 & 30.655 \\
\hline FIUIX & 1.398 & 13.813 \\
\hline FSUTX & 1.697 & 18.829 \\
\hline GEGTX & 1.727 & 19.483 \\
\hline HRCPX & 2.376 & 34.856 \\
\hline IDETX & 2.356 & 35.331 \\
\hline IDEUX & 1.874 & 24.913 \\
\hline IGLBX & 1.858 & 25.178 \\
\hline IGLCX & 2.488 & 39.982 \\
\hline JAMRX & 1.991 & 35.740 \\
\hline JAOSX & 1.870 & 23.264 \\
\hline JAVLX & 2.237 & 30.771 \\
\hline JAWWX & 1.946 & 20.705 \\
\hline LMVTX & 1.735 & 19.463 \\
\hline MAFGX & 1.849 & 20.490 \\
\hline MBFGX & 1.923 & 20.626 \\
\hline MCFGX & 2.463 & 60.247 \\
\hline MCOBX & 1.959 & 19.729 \\
\hline MCOFX & 1.875 & 18.821 \\
\hline MDFGX & 1.942 & 18.833 \\
\hline MGCAX & 1.789 & 31.720 \\
\hline MSEQX & 1.842 & 31.348 \\
\hline NAWCX & 1.318 & 24.631 \\
\hline NAWGX & 1.384 & 24.676 \\
\hline POVBX & 2.579 & 149.234 \\
\hline POVSX & 1.619 & 21.647 \\
\hline RYOSX & 2.690 & 42.951 \\
\hline SCGEX & 1.656 & 18.530 \\
\hline SRGFX & 2.224 & 40.412 \\
\hline SSGWX & 2.044 & 26.771 \\
\hline TALGX & 1.368 & 30.664 \\
\hline TRGEX & 1.786 & 25.739 \\
\hline TWIEX & 1.773 & 23.208 \\
\hline UMBIX & 1.823 & 12.379 \\
\hline
\end{tabular}

TABLE 3: Continued.

\begin{tabular}{lcc}
\hline Mutual fund & Expected return & Variance \\
\hline USBOX & 2.093 & 24.542 \\
VGHCX & 1.334 & 26.919 \\
VPMCX & 1.513 & 20.243 \\
WAGEX & 1.625 & 17.619 \\
WBIGX & 0.979 & 25.015 \\
FMAGX & 1.681 & 14.225 \\
JANSX & 2.643 & 35.453 \\
VFINX & 1.690 & 27.731 \\
VWNDX & 1.889 & 21.968 \\
\hline
\end{tabular}

The average of all $E_{k j}(k=1, \ldots, n)$

$$
\bar{E}_{j}=\frac{1}{n} \sum_{k=1}^{n} E_{k j}
$$

is used as the cross-efficiency score for $\mathrm{DMU}_{j}(j=1, \ldots, n)$.

Note that the cross-efficiency score obtained in the above manner can be negative. This subject is presented by a simple numerical example involving five DMUs, with two input and single output [13].

The negative VRS cross-efficiency score is due to the fact that $\sum_{r=1}^{s} u_{r k} y_{r j}-u_{0}<0$ for some $\mathrm{DMU}_{j}$; that is, some $\mathrm{DMU}_{j}$ will have negative efficiency ratios when they use a set of optimal weights obtained when $\mathrm{DMU}_{k}$ is under evaluation. Naturally, we want every output-input efficiency ratio to be positive regardless of the chosen weights. Therefore, adding $\sum_{r=1}^{s} u_{r k} y_{r j}-u_{0} \geq 0$ into the VRS model is proposed when calculating the cross-efficiency scores [13]. This will also guarantee nonnegativity of both VRS cross-efficiency scores and VRS efficiency ratios.

Therefore, the following modified VRS DEA model is used for model (10) development and application:

$$
\begin{array}{ll}
\max & \sum_{r=1}^{s} u_{r k} y_{r k}-u_{0} \\
\text { s.t. } & \sum_{r=1}^{s} u_{r k} y_{r j}-\sum_{i=1}^{m} v_{i k} x_{i j}-u_{0} \leq 0, \quad j=1, \ldots, n \\
& \sum_{i=1}^{m} v_{i k} x_{i k}=1 \\
& \sum_{r=1}^{s} u_{r k} y_{r j}-u_{0} \geq 0, \quad j=1,2, \ldots, n \\
& u_{r k} \geq 0, \quad r=1, \ldots, s \\
& v_{i k} \geq 0, \quad i=1, \ldots, m \\
& u_{0} \geq 0 .
\end{array}
$$

\section{Methodology}

Return of assets consists of money which we receive among period plus difference of buying and selling. Return is 
TABLE 4: OWA operator weights for cross efficiency evaluation.

\begin{tabular}{|c|c|c|c|c|c|c|c|c|c|c|}
\hline$\alpha=1$ & $\alpha=0.9613$ & $\alpha=0.9$ & $\alpha=0.8$ & $\alpha=0.7$ & $\alpha=0.6$ & $\alpha=0.5$ & $\alpha=0.4$ & $\alpha=0.3$ & $\alpha=0.2$ & $\alpha=0.1$ \\
\hline 1 & 0.2 & 0.106 & 0.056 & 0.038 & 0.028 & 0.018 & 0.007 & 0 & 0 & 0 \\
\hline 0 & 0.178 & 0.1 & 0.055 & 0.037 & 0.027 & 0.018 & 0.008 & 0 & 0 & 0 \\
\hline 0 & 0.156 & 0.094 & 0.053 & 0.037 & 0.027 & 0.018 & 0.008 & 0 & 0 & 0 \\
\hline 0 & 0.134 & 0.088 & 0.051 & 0.036 & 0.027 & 0.018 & 0.008 & 0 & 0 & 0 \\
\hline 0 & 0.112 & 0.082 & 0.05 & 0.035 & 0.026 & 0.018 & 0.009 & 0 & 0 & 0 \\
\hline 0 & 0.09 & 0.077 & 0.048 & 0.034 & 0.026 & 0.018 & 0.009 & $3.00 E-04$ & 0 & 0 \\
\hline 0 & 0.068 & 0.071 & 0.046 & 0.034 & 0.026 & 0.018 & 0.01 & 0.001 & 0 & 0 \\
\hline 0 & 0.046 & 0.065 & 0.045 & 0.033 & 0.025 & 0.018 & 0.01 & 0.002 & 0 & 0 \\
\hline 0 & 0.024 & 0.059 & 0.043 & 0.032 & 0.025 & 0.018 & 0.01 & 0.003 & 0 & 0 \\
\hline 0 & 0.002 & 0.053 & 0.042 & 0.031 & 0.024 & 0.018 & 0.011 & 0.003 & 0 & 0 \\
\hline 0 & 0 & 0.047 & 0.04 & 0.031 & 0.024 & 0.018 & 0.011 & 0.004 & 0 & 0 \\
\hline 0 & 0 & 0.041 & 0.038 & 0.03 & 0.024 & 0.018 & 0.011 & 0.005 & 0 & 0 \\
\hline 0 & 0 & 0.035 & 0.037 & 0.029 & 0.023 & 0.018 & 0.012 & 0.005 & 0 & 0 \\
\hline 0 & 0 & 0.029 & 0.035 & 0.029 & 0.023 & 0.018 & 0.012 & 0.006 & 0 & 0 \\
\hline 0 & 0 & 0.023 & 0.033 & 0.028 & 0.023 & 0.018 & 0.012 & 0.007 & 0 & 0 \\
\hline 0 & 0 & 0.017 & 0.032 & 0.027 & 0.022 & 0.018 & 0.013 & 0.008 & 0 & 0 \\
\hline 0 & 0 & 0.011 & 0.03 & 0.026 & 0.022 & 0.018 & 0.013 & 0.008 & 0 & 0 \\
\hline 0 & 0 & 0.005 & 0.029 & 0.026 & 0.022 & 0.018 & 0.014 & 0.009 & 0 & 0 \\
\hline 0 & 0 & 0 & 0.027 & 0.025 & 0.021 & 0.018 & 0.014 & 0.01 & 0 & 0 \\
\hline 0 & 0 & 0 & 0.025 & 0.024 & 0.021 & 0.018 & 0.014 & 0.011 & 0 & 0 \\
\hline 0 & 0 & 0 & 0.024 & 0.023 & 0.02 & 0.018 & 0.015 & 0.011 & 0 & 0 \\
\hline 0 & 0 & 0 & 0.022 & 0.023 & 0.02 & 0.018 & 0.015 & 0.012 & 0 & 0 \\
\hline 0 & 0 & 0 & 0.02 & 0.022 & 0.02 & 0.018 & 0.015 & 0.013 & 0 & 0 \\
\hline 0 & 0 & 0 & 0.019 & 0.021 & 0.019 & 0.018 & 0.016 & 0.014 & 0.003 & 0 \\
\hline 0 & 0 & 0 & 0.017 & 0.02 & 0.019 & 0.018 & 0.016 & 0.014 & 0.004 & 0 \\
\hline 0 & 0 & 0 & 0.016 & 0.02 & 0.019 & 0.018 & 0.016 & 0.015 & 0.006 & 0 \\
\hline 0 & 0 & 0 & 0.014 & 0.019 & 0.018 & 0.018 & 0.017 & 0.016 & 0.007 & 0 \\
\hline 0 & 0 & 0 & 0.012 & 0.018 & 0.018 & 0.018 & 0.017 & 0.017 & 0.009 & 0 \\
\hline 0 & 0 & 0 & 0.011 & 0.017 & 0.018 & 0.018 & 0.018 & 0.017 & 0.011 & 0 \\
\hline 0 & 0 & 0 & 0.009 & 0.017 & 0.017 & 0.018 & 0.018 & 0.018 & 0.012 & 0 \\
\hline 0 & 0 & 0 & 0.007 & 0.016 & 0.017 & 0.018 & 0.018 & 0.019 & 0.014 & 0 \\
\hline 0 & 0 & 0 & 0.006 & 0.015 & 0.016 & 0.018 & 0.019 & 0.02 & 0.016 & 0 \\
\hline 0 & 0 & 0 & 0.004 & 0.014 & 0.016 & 0.018 & 0.019 & 0.02 & 0.017 & 0 \\
\hline 0 & 0 & 0 & 0.003 & 0.014 & 0.016 & 0.018 & 0.019 & 0.021 & 0.019 & 0 \\
\hline 0 & 0 & 0 & 0 & 0.013 & 0.015 & 0.018 & 0.02 & 0.022 & 0.02 & 0 \\
\hline 0 & 0 & 0 & 0 & 0.012 & 0.015 & 0.018 & 0.02 & 0.023 & 0.022 & 0 \\
\hline 0 & 0 & 0 & 0 & 0.011 & 0.015 & 0.018 & 0.02 & 0.023 & 0.024 & 0 \\
\hline 0 & 0 & 0 & 0 & 0.011 & 0.014 & 0.018 & 0.021 & 0.024 & 0.025 & 0 \\
\hline 0 & 0 & 0 & 0 & 0.01 & 0.014 & 0.018 & 0.021 & 0.025 & 0.027 & 0 \\
\hline 0 & 0 & 0 & 0 & 0.009 & 0.014 & 0.018 & 0.022 & 0.026 & 0.029 & 0.005 \\
\hline 0 & 0 & 0 & 0 & 0.008 & 0.013 & 0.018 & 0.022 & 0.026 & 0.03 & 0.011 \\
\hline 0 & 0 & 0 & 0 & 0.008 & 0.013 & 0.018 & 0.022 & 0.027 & 0.032 & 0.017 \\
\hline 0 & 0 & 0 & 0 & 0.007 & 0.012 & 0.018 & 0.023 & 0.028 & 0.033 & 0.023 \\
\hline 0 & 0 & 0 & 0 & 0.006 & 0.012 & 0.018 & 0.023 & 0.029 & 0.035 & 0.029 \\
\hline 0 & 0 & 0 & 0 & 0.005 & 0.012 & 0.018 & 0.023 & 0.029 & 0.037 & 0.035 \\
\hline 0 & 0 & 0 & 0 & 0.005 & 0.011 & 0.018 & 0.024 & 0.03 & 0.038 & 0.041 \\
\hline 0 & 0 & 0 & 0 & 0.004 & 0.011 & 0.018 & 0.024 & 0.031 & 0.04 & 0.047 \\
\hline 0 & 0 & 0 & 0 & 0.003 & 0.011 & 0.018 & 0.024 & 0.031 & 0.042 & 0.053 \\
\hline
\end{tabular}


TABLE 4: Continued.

\begin{tabular}{cccccccccccc}
\hline$\alpha=1$ & $\alpha=0.9613$ & $\alpha=0.9$ & $\alpha=0.8$ & $\alpha=0.7$ & $\alpha=0.6$ & $\alpha=0.5$ & $\alpha=0.4$ & $\alpha=0.3$ & $\alpha=0.2$ & $\alpha=0.1$ \\
\hline 0 & 0 & 0 & 0 & 0.003 & 0.01 & 0.018 & 0.025 & 0.032 & 0.043 & 0.059 \\
0 & 0 & 0 & 0 & 0.002 & 0.01 & 0.018 & 0.025 & 0.033 & 0.045 & 0.065 \\
0 & 0 & 0 & 0 & 0.001 & 0.01 & 0.018 & 0.026 & 0.034 & 0.046 & 0.071 \\
0 & 0 & 0 & 0 & $3.00 E-04$ & 0.009 & 0.018 & 0.026 & 0.034 & 0.048 & 0.077 \\
0 & 0 & 0 & 0 & 0 & 0.009 & 0.018 & 0.026 & 0.035 & 0.05 & 0.082 \\
0 & 0 & 0 & 0 & 0 & 0.008 & 0.018 & 0.027 & 0.036 & 0.051 & 0.088 \\
0 & 0 & 0 & 0 & 0 & 0.008 & 0.018 & 0.027 & 0.037 & 0.053 & 0.094 \\
0 & 0 & 0 & 0 & 0 & 0.008 & 0.018 & 0.027 & 0.037 & 0.055 & 0.1 \\
0 & 0 & 0 & 0 & 0 & 0.007 & 0.018 & 0.028 & 0.038 & 0.056 & 0.106 \\
\hline
\end{tabular}

not definitely usually obvious. This is uncertain in rate of expected return defined as deviation of return. Deviation of return is called risk. The investor's objective is to get the maximum possible return on an investment with the minimum possible risk. In this regard, mean-variance model Markowitz expected return is treated as output and deviation as input. The methodology in this paper starts with asset selection via cross-efficiency evaluation using OWA operator weights. The data used for this methodology is from 57 mutual funds [5]. In many cases similar to this example, there are a lot of assets. It is better that starts with asset selection. The choice of the asset can be random or discrete. The random choice of assets is usually biased and does not promise an optimum portfolio; hence, it is more rational to have an objective choice while selecting the assets to be included in the portfolio. Among many evaluation methods, Data Envelopment Analysis (DEA) is one of the best ways for assessing the relative efficiency a group of homogenous decision making units (DMUs) that use multiple inputs to produce multiple outputs, originated from the work by Charnes et al. [3]. Selection of assets to be included in portfolio is followed by using cross-efficiency in DEA. The variable returns to scale (VRS) DEA model is used for efficiency evaluation. In the analysis, the variance of the assets is used as an input to the DEA and expected return is used as an output. Because the VRS DEA model can generate negative crossefficiency score, thus model (13) is proposed so that the crossefficiency scores are nonnegative. Traditional approaches for the cross-efficiency evaluation do not differentiate between self-evaluated and peer-evaluated efficiencies. A significant problem with these approaches is that the weight assigned to the self-evaluated efficiency of each DMU is fixed and has no way of incorporating the DM's or investor's subjective preferences in to the evaluation. For example, the investors may wish self-evaluated efficiencies to account for $20 \%$ or play a leading role in the final overall efficiency assessment. Obviously, equal evaluation has no method to obtain this purpose. To show the investor's subjective preferences on different efficiencies, the use of OWA operator weights is stated for cross-efficiency evaluation (see Table 4). This requires the reordering of the efficiencies, both self-evaluated and peer-evaluated, of each DMU, as shown in Table 2, where $w_{1}, \ldots, w_{n}$ are OWA operator weights and $\vartheta_{i j}(i, j=1, \ldots, n)$ are reordered efficiencies of each DMU from the biggest to the smallest. Obviously, self-evaluated efficiencies are always ranked in the first place; that is, $\vartheta_{i 1}=\theta_{i i}^{*}, i=1, \ldots, n$. In order to determine the weights of OWA operator, it is necessary for the investor to provide his/her preferences on different efficiencies or optimism level towards the best relative efficiencies. For example, if the investor wants the selfevaluated efficiencies to account for $20 \%$ in the final overall efficiency assessment, then $w_{1}$ should take 0.2 , whereas the other weights can be designated minimax disparity approach. With regard to the minimax disparity OWA operator weights, the following theorems are existed [17].

Theorem 1. For a given $w_{1}$, there exists an integer $k \leq n$ such that $w_{i}=w_{1}-(i-1) d \geq 0$ for $i=1, \ldots, k$ and $w_{i}=0$ for $i=k+1, \ldots, n$, where $k$ and $d$ are determined by

$$
k=\min \left(n, \operatorname{INT}\left[\frac{2}{w_{1}}\right]\right), \quad d=\frac{2\left(k w_{1}-1\right)}{k(k-1)} .
$$

Theorem 2. For a given orness degree $\alpha \in(0.5,1)$, there exists an integer $k \leq n$ such that $w_{i}=w_{1}-(i-1) d \geq 0$ for $i=$ $1, \ldots, k$ and $w_{i}=0$ for $i=k+1, \ldots, n$, where $k, w_{1}$, and $d$ are determined by

$$
w_{1}=\frac{4(k+1)-6 n+6 \alpha(n-1)}{k(k+1)}, \quad d=\frac{2\left(k w_{1}-1\right)}{k(k-1)} .
$$

In this paper, the OWA operator weights can be determined by using the minimax disparity approach. In the following, some very special OWA operator weights for the cross-efficiency evaluation are given.

Consider $w_{1}=1$ and $w_{j}=0(j \neq 1)$. In this case, $\operatorname{orness}(W)=1$ and $\bar{\theta}_{i}=\sum_{k=1}^{n} w_{k} \vartheta_{i k}=\vartheta_{i 1}=\theta_{i i}^{*}$ for $i=1, \ldots, n$. The investor considers only self-evaluated efficiencies in the final overall efficiency assessment and is purely optimistic.

Consider $w_{n}=1$ and $w_{j}=0(j \neq 1)$. In this case, $\operatorname{orness}(W)=0$ and $\bar{\theta}_{i}=\sum_{k=1}^{n} w_{k} \vartheta_{i k}=\vartheta_{i n}=\min _{k}\left(\theta_{i k}\right)$ for $i=1, \ldots, n$. The investor chooses the least efficiency value of each DMU as its overall efficiency and is extremely pessimistic.

Consider $w_{1}, \ldots, w_{n}=1 / n$. In this case, orness $(W)=0.5$ and $\bar{\theta}_{i}=\sum_{k=1}^{n} w_{k} \vartheta_{i k}=(1 / n) \sum_{k=1}^{n} \theta_{i k}$ for $i=1, \ldots, n$, which is the average cross-efficiency value in the traditional crossefficiency evaluation. 
TABLE 5: Cross efficiency by optimism level of the investor for $\alpha \geq 0.5$.

\begin{tabular}{|c|c|c|c|c|c|c|c|c|c|c|}
\hline DMU & Mutual funds & VRS efficiency & $\alpha=1$ & $\alpha=0.9613$ & $\alpha=0.9$ & $\alpha=0.8$ & $\alpha=0.7$ & $\alpha=0.6$ & $\alpha=0.5$ & $\begin{array}{c}\text { Ranking } \\
\alpha=0.8 \\
\end{array}$ \\
\hline 1 & ACEFX & 0.32 & 0.324 & 0.323 & 0.323 & 0.319 & 0.312 & 0.306 & 0.308 & 50 \\
\hline 2 & ACEGX & 0.33 & 0.334 & 0.333 & 0.333 & 0.328 & 0.322 & 0.315 & 0.317 & 48 \\
\hline 3 & ACEMX & 0.32 & 0.324 & 0.287 & 0.323 & 0.319 & 0.312 & 0.306 & 0.308 & 49 \\
\hline 4 & AELAX & 0.37 & 0.370 & 0.373 & 0.370 & 0.363 & 0.350 & 0.3392 & 0.336 & 44 \\
\hline 5 & AELGX & 0.38 & 0.377 & 0.371 & 0.383 & 0.377 & 0.365 & 0.3550 & 0.353 & 43 \\
\hline 6 & AGTHX & 0.56 & 0.569 & 0.572 & 0.566 & 0.560 & 0.558 & 0.556 & 0.568 & 21 \\
\hline 7 & ARCGX & 0.46 & 0.472 & 0.454 & 0.468 & 0.463 & 0.459 & 0.456 & 0.465 & 34 \\
\hline 8 & AVLFX & 0.55 & 0.560 & 0.563 & 0.558 & 0.552 & 0.546 & 0.541 & 0.549 & 22 \\
\hline 9 & BJBIX & 0.31 & 0.311 & 0.313 & 0.310 & 0.307 & 0.301 & 0.297 & 0.300 & 51 \\
\hline 10 & CUCAX & 0.56 & 0.572 & 0.564 & 0.568 & 0.561 & 0.558 & 0.554 & 0.565 & 20 \\
\hline 11 & FAGIX & 0.66 & 0.669 & 0.667 & 0.670 & 0.627 & 0.509 & 0.410 & 0.320 & 9 \\
\hline 12 & FAIAX & 0.24 & 0.246 & 0.248 & 0.246 & 0.242 & 0.236 & 0.232 & 0.233 & 55 \\
\hline 13 & FAICX & 0.25 & 0.249 & 0.251 & 0.249 & 0.245 & 0.239 & 0.235 & 0.236 & 54 \\
\hline 14 & FDEGX & 0.35 & 0.351 & 0.352 & 0.349 & 0.345 & 0.339 & 0.334 & 0.337 & 46 \\
\hline 15 & FEURX & 0.38 & 0.379 & 0.382 & 0.378 & 0.3751 & 0.372 & 0.370 & 0.377 & 42 \\
\hline 16 & FIUIX & 0.69 & 0.694 & 0.693 & 0.693 & 0.683 & 0.667 & 0.653 & 0.655 & 6 \\
\hline 17 & FSUTX & 0.61 & 0.618 & 0.615 & 0.620 & 0.611 & 0.607 & 0.603 & 0.615 & 13 \\
\hline 18 & GEGTX & 0.60 & 0.608 & 0.605 & 0.607 & 0.601 & 0.598 & 0.595 & 0.607 & 16 \\
\hline 19 & HRCPX & 0.51 & 0.516 & 0.518 & 0.512 & 0.506 & 0.498 & 0.491 & 0.496 & 27 \\
\hline 20 & IDETX & 0.50 & 0.503 & 0.505 & 0.500 & 0.494 & 0.486 & 0.480 & 0.485 & 31 \\
\hline 21 & IDEUX & 0.52 & 0.525 & 0.527 & 0.521 & 0.517 & 0.515 & 0.513 & 0.525 & 26 \\
\hline 22 & IGLBX & 0.50 & 0.513 & 0.515 & 0.510 & 0.506 & 0.504 & 0.503 & 0.514 & 28 \\
\hline 23 & IGLCX & 0.47 & 0.477 & 0.478 & 0.474 & 0.468 & 0.459 & 0.452 & 0.456 & 34 \\
\hline 24 & JAMRX & 0.39 & 0.398 & 0.399 & 0.395 & 0.390 & 0.388 & 0.386 & 0.393 & 39 \\
\hline 25 & JAOSX & 0.55 & 0.561 & 0.562 & 0.557 & 0.552 & 0.550 & 0.548 & 0.560 & 19 \\
\hline 26 & JAVLX & 0.53 & 0.540 & 0.542 & 0.536 & 0.530 & 0.523 & 0.517 & 0.524 & 24 \\
\hline 27 & JAWWX & 0.65 & 0.666 & 0.668 & 0.661 & 0.654 & 0.650 & 0.647 & 0.661 & 7 \\
\hline 28 & LMVTX & 0.61 & 0.611 & 0.604 & 0.610 & 0.605 & 0.602 & 0.599 & 0.611 & 15 \\
\hline 29 & MAFGX & 0.62 & 0.627 & 0.628 & 0.622 & 0.618 & 0.616 & 0.614 & 0.628 & 10 \\
\hline 30 & MBFGX & 0.65 & 0.657 & 0.659 & 0.653 & 0.646 & 0.643 & 0.640 & 0.654 & 8 \\
\hline 31 & MCFGX & 0.31 & 0.312 & 0.314 & 0.310 & 0.306 & 0.301 & 0.299 & 0.282 & 52 \\
\hline 32 & MCOBX & 0.69 & 0.705 & 0.707 & 0.700 & 0.693 & 0.688 & 0.685 & 0.699 & 4 \\
\hline 33 & MCOFX & 0.68 & 0.696 & 0.698 & 0.691 & 0.685 & 0.682 & 0.680 & 0.695 & 5 \\
\hline 34 & MDFGX & 0.72 & 0.730 & 0.732 & 0.725 & 0.717 & 0.713 & 0.710 & 0.725 & 3 \\
\hline 35 & MGCAX & 0.38 & 0.387 & 0.387 & 0.386 & 0.383 & 0.382 & 0.381 & 0.389 & 40 \\
\hline 36 & MSEQX & 0.40 & 0.407 & 0.409 & 0.405 & 0.402 & 0.400 & 0.399 & 0.408 & 36 \\
\hline 37 & NAWCX & 0.36 & 0.367 & 0.312 & 0.366 & 0.360 & 0.350 & 0.340 & 0.340 & 45 \\
\hline 38 & NAWGX & 0.38 & 0.385 & 0.337 & 0.384 & 0.378 & 0.369 & 0.361 & 0.362 & 41 \\
\hline 39 & POVBX & 0.13 & 0.134 & 0.134 & 0.133 & 0.131 & 0.128 & 0.126 & 0.127 & 57 \\
\hline 40 & POVSX & 0.51 & 0.513 & 0.511 & 0.512 & 0.506 & 0.501 & 0.497 & 0.504 & 30 \\
\hline 41 & RYOSX & 0.48 & 0.490 & 0.492 & 0.486 & 0.480 & 0.470 & 0.462 & 0.465 & 32 \\
\hline 42 & SCGEX & 0.61 & 0.613 & 0.593 & 0.612 & 0.606 & 0.600 & 0.596 & 0.606 & 14 \\
\hline 43 & SRGFX & 0.40 & 0.408 & 0.410 & 0.405 & 0.401 & 0.395 & 0.391 & 0.396 & 38 \\
\hline 44 & SSGWX & 0.54 & 0.551 & 0.552 & 0.547 & 0.541 & 0.536 & 0.532 & 0.542 & 23 \\
\hline 45 & TALGX & 0.30 & 0.306 & 0.266 & 0.305 & 0.301 & 0.293 & 0.286 & 0.287 & 53 \\
\hline 46 & TRGEX & 0.47 & 0.476 & 0.476 & 0.475 & 0.472 & 0.470 & 0.469 & 0.479 & 33 \\
\hline 47 & TWIEX & 0.52 & 0.524 & 0.523 & 0.523 & 0.519 & 0.517 & 0.515 & 0.526 & 25 \\
\hline
\end{tabular}


TABLe 5: Continued.

\begin{tabular}{lcccccccccc}
\hline DMU & Mutual funds & VRS efficiency & $\alpha=1$ & $\alpha=0.9613$ & $\alpha=0.9$ & $\alpha=0.8$ & $\alpha=0.7$ & $\begin{array}{c}\alpha=0.6 \\
\alpha=0.5\end{array} \begin{array}{c}\text { Ranking } \\
\alpha=0.8\end{array}$ \\
\hline 48 & UMBIX & $\mathbf{1 . 0 0}$ & $\mathbf{1 . 0 0 0}$ & $\mathbf{1 . 0 2 0}$ & $\mathbf{1 . 0 1 2}$ & $\mathbf{1 . 0 0 5}$ & $\mathbf{1 . 0 0 2}$ & $\mathbf{1 . 0 2 1}$ & $\mathbf{0 . 9 8 8}$ & $\mathbf{1}$ \\
49 & USBOX & 0.61 & 0.620 & 0.622 & 0.616 & 0.609 & 0.603 & 0.598 & 0.608 & 12 \\
50 & VGHCX & 0.34 & 0.342 & 0.339 & 0.342 & 0.336 & 0.327 & 0.3191 & 0.319 & 47 \\
51 & VPMCX & 0.51 & 0.513 & 0.473 & 0.512 & 0.505 & 0.497 & 0.490 & 0.495 & 29 \\
52 & WAGEX & 0.63 & 0.633 & 0.627 & 0.631 & 0.624 & 0.618 & 0.613 & 0.623 & 10 \\
53 & WBIGX & 0.27 & 0.174 & 0.174 & 0.172 & 0.172 & 0.187 & 0.201 & 0.220 & 56 \\
54 & FMAGX & $\mathbf{0 . 8 0}$ & $\mathbf{0 . 8 1 0}$ & $\mathbf{0 . 7 9 0}$ & $\mathbf{0 . 8 0 8}$ & $\mathbf{0 . 8 0 1}$ & $\mathbf{0 . 7 9 5}$ & $\mathbf{0 . 7 9 0}$ & $\mathbf{0 . 8 0 4}$ & $\mathbf{2}$ \\
55 & JANSX & 0.57 & 0.580 & 0.583 & 0.576 & 0.569 & 0.558 & 0.548 & 0.552 & 18 \\
56 & VFINX & 0.41 & 0.418 & 0.408 & 0.417 & 0.413 & 0.410 & 0.408 & 0.415 & 36 \\
57 & VWNDX & 0.59 & 0.602 & 0.583 & 0.597 & 0.592 & 0.590 & 0.588 & 0.601 & 17 \\
\hline
\end{tabular}

The orness degree can be regarded as a measure of the optimism level of the investor. If the investor wants selfevaluated to be more influenced, it should be used of orness $>0.5$. And if investor wants peer-evaluated to be more influenced, it should be used of orness $<0.5$. Obviously, the best selection of mutual funds is not fixed. It varies with the investor's optimism level or subjective performance.

\section{Application in Mutual Funds}

We illustrate our approach using OWA operator weights in cross-efficiency evaluation for a dataset of 57 mutual funds. A list of funds used is provided in Table 3. In this report, there is expected return and variance of mutual funds which expected return is considered as output and variance is as input. The example is received from Joro and $\mathrm{Na}$ [5] and is about portfolio performance evaluation in a mean-variance framework. Four mutual funds are evaluated as efficient in model [1] which portfolio can be composed with them. But it is better to use cross-efficiency to choose the best portfolio. Because the model (10) can generate negative crossefficiency score, thus model (13) is used so that the crossefficiency scores are nonnegative. Traditional approaches for the cross-efficiency evaluation do not differentiate between self-evaluated and peer-evaluated efficiencies. A main problem with these approaches is that the weight assigned to the self-evaluated efficiency of each DMU is fixed and has no way of incorporating the investor's subjective preferences into the evaluation. Obviously, equal evaluation has no way to obtain this goal. To show the investor's subjective preferences on different efficiencies, the use of OWA operator weights is stated for cross-efficiency evaluation. This requires the reordering of the efficiencies. The orness degree can be regarded as a measure of the optimism level of the investor. If the investor wants self-evaluated to be more influenced, it should be used of orness $>0.5$. And if investor wants peerevaluated to be more influenced, it should be used of orness $<0.5$. In the traditional equal of cross-efficiencies, the weight assigned to the self-evaluated efficiencies is only $0.017 \%=$ $(1 / 57)$. For an optimistic investor, he/she may wish the selfevaluated efficiencies to play a more role in the final overall efficiency assessment. For example, the investor may wish the weight for the self-evaluated efficiencies to account for $20 \%$ rather than $0.017 \%$ in the final overall efficiency assessment. By Theorem $1, k=\min (57, \operatorname{INT}[2 / 0.2])=10$ and $d=$ $2\left(k w_{1}-1\right) / k(k-1)=2(10 \times 0.2-1) /(10 \times 9)=0.022$ are obtained. As a result, the weights for cross-efficiency are computed as $w_{1}=0.2, w_{2}=w_{1}-d=0.178, w_{3}=$ $w_{1}-2 d=0.156, w_{4}=w_{1}-3 d=0.134, w_{5}=w_{1}-4 d=$ $0.112, w_{6}=w_{1}-5 d=0.09, \quad w_{7}=w_{1}-6 d=0.068, w_{8}=$ $w_{1}-7 d=0.046, w_{9}=w_{1}-8 d=0.024, w_{10}=w_{1}-9 d=$ 0.002 , and $w_{11}=\cdots=w_{57}=0$. The investor's optimism level is measured as orness $(W)=(1 /(n-1)) \sum_{i=1}^{n}(n-i) w_{i}=0.9613$. The weighted average cross-efficiency values of the 57 mutual funds are computed by $\bar{\theta}_{i}=\sum_{k=1}^{n} w_{k} \vartheta_{i k}$ for $i=1, \ldots, n$ and the results are presented in the fifth column of the Table 5. As is seen in Tables 5 and 6 , ranks are not the same. We calculated these ranks for $\alpha=0.8$ and $\alpha=0.1$. Some of the best ranks are designated according to investor. We consider ten of the best ranks. Five of the best ranks become the same, in this example,incidentally. Selecting of mutual funds to be included in portfolio is followed by ten of the best ranks in Tables 7 and 8 for $\alpha \geq 0.5, \alpha \leq 0.4$, respectively.

\section{Conclusion}

In this paper, a new method is suggested for selecting the best of portfolio with one input (variance) and one output (expected return) in the DEA context. As an advanced management decision tool, DEA has been widely used for performance evaluation $[24,25]$, productivity analysis [2628], resource allocation [29], and so on. The cross-efficiency evaluation is an important method for ranking DMUs in DEA. Traditional approaches for the cross-efficiency evaluation do not differentiate between self-evaluated and peerevaluated efficiencies. A main problem with these approaches is that the weight assigned to the self-evaluated efficiency of each DMU is fixed and has no way of incorporating the investor's subjective preferences in to the evaluation. To show the investor's subjective preferences on different efficiencies, the use of OWA operator weights is stated for cross-efficiency evaluation. In this case, if the investor wants self-evaluated 
TABLE 6: Cross efficiency by OWA operator weights for $\alpha \leq 0.4$.

\begin{tabular}{|c|c|c|c|c|c|c|c|}
\hline DMU & Mutual funds & VRS efficiency & $\alpha=0.4$ & $\alpha=0.3$ & $\alpha=0.2$ & $\alpha=0.1$ & $\begin{array}{c}\text { Ranking } \\
\alpha=0.1\end{array}$ \\
\hline 1 & ACEFX & 0.32 & 0.295 & 0.288 & 0.282 & 0.282 & 48 \\
\hline 2 & ACEGX & 0.33 & 0.302 & 0.296 & 0.289 & 0.287 & 46 \\
\hline 3 & ACEMX & 0.32 & 0.295 & 0.288 & 0.282 & 0.281 & 49 \\
\hline 4 & AELAX & 0.37 & 0.316 & 0.305 & 0.293 & 0.291 & 45 \\
\hline 5 & AELGX & 0.38 & 0.334 & 0.323 & 0.312 & 0.310 & 43 \\
\hline 6 & AGTHX & 0.56 & 0.551 & 0.548 & 0.545 & 0.545 & 17 \\
\hline 7 & ARCGX & 0.46 & 0.450 & 0.446 & 0.443 & 0.443 & 32 \\
\hline 8 & AVLFX & 0.55 & 0.530 & 0.524 & 0.518 & 0.515 & 20 \\
\hline 9 & BJBIX & 0.31 & 0.288 & 0.283 & 0.278 & 0.276 & 49 \\
\hline 10 & CUCAX & 0.56 & 0.547 & 0.543 & 0.540 & 0.539 & 18 \\
\hline 11 & FAGIX & 0.66 & 0.213 & 0.115 & 0.011 & 0 & 57 \\
\hline 12 & FAIAX & 0.24 & 0.222 & 0.217 & 0.211 & 0.210 & 55 \\
\hline 13 & FAICX & 0.25 & 0.225 & 0.220 & 0.215 & 0.214 & 54 \\
\hline 14 & FDEGX & 0.35 & 0.323 & 0.318 & 0.312 & 0.311 & 42 \\
\hline 15 & FEURX & 0.38 & 0.365 & 0.362 & 0.359 & 0.358 & 40 \\
\hline 16 & FIUIX & 0.69 & 0.625 & 0.610 & 0.595 & 0.591 & 9 \\
\hline 17 & FSUTX & 0.61 & 0.595 & 0.590 & 0.586 & 0.584 & 11 \\
\hline 18 & GEGTX & 0.60 & 0.588 & 0.585 & 0.581 & 0.578 & 13 \\
\hline 19 & HRCPX & 0.51 & 0.477 & 0.469 & 0.461 & 0.460 & 28 \\
\hline 20 & IDETX & 0.50 & 0.466 & 0.459 & 0.451 & 0.450 & 31 \\
\hline 21 & IDEUX & 0.52 & 0.509 & 0.507 & 0.505 & 0.504 & 23 \\
\hline 22 & IGLBX & 0.50 & 0.499 & 0.497 & 0.494 & 0.494 & 25 \\
\hline 23 & IGLCX & 0.47 & 0.437 & 0.430 & 0.421 & 0.420 & 34 \\
\hline 24 & JAMRX & 0.39 & 0.381 & 0.378 & 0.376 & 0.375 & 35 \\
\hline 25 & JAOSX & 0.55 & 0.544 & 0.542 & 0.539 & 0.539 & 19 \\
\hline 26 & JAVLX & 0.53 & 0.505 & 0.498 & 0.492 & 0.490 & 26 \\
\hline 27 & JAWWX & 0.65 & 0.640 & 0.637 & 0.633 & 0.633 & 6 \\
\hline 28 & LMVTX & 0.61 & 0.592 & 0.589 & 0.585 & 0.583 & 12 \\
\hline 29 & MAFGX & 0.62 & 0.609 & 0.607 & 0.604 & 0.603 & 8 \\
\hline 30 & MBFGX & 0.65 & 0.634 & 0.631 & 0.627 & 0.627 & 7 \\
\hline 31 & MCFGX & 0.31 & 0.287 & 0.282 & 0.277 & 0.276 & 51 \\
\hline 32 & MCOBX & 0.69 & 0.677 & 0.673 & 0.669 & 0.669 & 4 \\
\hline 33 & MCOFX & 0.68 & 0.675 & 0.672 & 0.669 & 0.668 & 5 \\
\hline 34 & MDFGX & 0.72 & 0.702 & 0.698 & 0.695 & 0.694 & 3 \\
\hline 35 & MGCAX & 0.38 & 0.378 & 0.376 & 0.374 & 0.373 & 38 \\
\hline 36 & MSEQX & 0.40 & 0.396 & 0.395 & 0.393 & 0.392 & 36 \\
\hline 37 & NAWCX & 0.36 & 0.322 & 0.313 & 0.303 & 0.300 & 44 \\
\hline 38 & NAWGX & 0.38 & 0.345 & 0.336 & 0.327 & 0.325 & 41 \\
\hline 39 & POVBX & 0.13 & 0.122 & 0.119 & 0.117 & 0.116 & 56 \\
\hline 40 & POVSX & 0.51 & 0.486 & 0.481 & 0.475 & 0.473 & 27 \\
\hline 41 & RYOSX & 0.48 & 0.444 & 0.435 & 0.425 & 0.422 & 33 \\
\hline 42 & SCGEX & 0.61 & 0.586 & 0.580 & 0.574 & 0.572 & 16 \\
\hline 43 & SRGFX & 0.40 & 0.382 & 0.377 & 0.372 & 0.371 & 39 \\
\hline 44 & SSGWX & 0.54 & 0.524 & 0.519 & 0.515 & 0.515 & 21 \\
\hline 45 & TALGX & 0.30 & 0.273 & 0.266 & 0.258 & 0.257 & 53 \\
\hline 46 & TRGEX & 0.47 & 0.465 & 0.463 & 0.460 & 0.459 & 29 \\
\hline
\end{tabular}


TABLE 6: Continued.

\begin{tabular}{|c|c|c|c|c|c|c|c|}
\hline $\mathrm{DMU}$ & Mutual funds & VRS efficiency & $\alpha=0.4$ & $\alpha=0.3$ & $\alpha=0.2$ & $\alpha=0.1$ & $\begin{array}{c}\text { Ranking } \\
\alpha=0.1\end{array}$ \\
\hline 47 & TWIEX & 0.52 & 0.511 & 0.508 & 0.505 & 0.504 & 22 \\
\hline 48 & UMBIX & 1.00 & 0.992 & 0.988 & 0.983 & 0.981 & 1 \\
\hline 49 & USBOX & 0.61 & 0.587 & 0.581 & 0.576 & 0.575 & 15 \\
\hline 50 & VGHCX & 0.34 & 0.303 & 0.295 & 0.286 & 0.284 & 47 \\
\hline 51 & VPMCX & 0.51 & 0.475 & 0.467 & 0.459 & 0.457 & 30 \\
\hline 52 & WAGEX & 0.63 & 0.601 & 0.594 & 0.588 & 0.585 & 10 \\
\hline 53 & WBIGX & 0.27 & 0.228 & 0.242 & 0.259 & 0.264 & 52 \\
\hline 54 & FMAGX & 0.80 & 0.778 & 0.772 & 0.765 & 0.761 & 2 \\
\hline 55 & JANSX & 0.57 & 0.527 & 0.517 & 0.505 & 0.503 & 24 \\
\hline 56 & VFINX & 0.41 & 0.402 & 0.398 & 0.395 & 0.394 & 35 \\
\hline 57 & VWNDX & 0.59 & 0.583 & 0.580 & 0.578 & 0.577 & 14 \\
\hline
\end{tabular}

TABLE 7: Selecting the best assets for making portfolio for $\alpha \geq 0.5$.

\begin{tabular}{lcccc}
\hline & & Expected return & Variance & Ranking \\
\hline 48 & UMBIX & 1.833 & 12.379 & 1 \\
54 & FMAGX & 1.681 & 14.225 & 2 \\
34 & MDFGX & 1.942 & 18.833 & 3 \\
32 & MCOBX & 1.959 & 19.729 & 4 \\
33 & MCOFX & 1.875 & 18.821 & 5 \\
16 & FIUIX & $\mathbf{1 . 3 9 8}$ & $\mathbf{1 3 . 8 1 3}$ & $\mathbf{6}$ \\
27 & JAWWX & $\mathbf{1 . 9 4 6}$ & $\mathbf{2 0 . 7 0 5}$ & $\mathbf{7}$ \\
30 & MBFGX & $\mathbf{1 . 9 2 3}$ & $\mathbf{2 0 . 6 2 6}$ & $\mathbf{8}$ \\
11 & FAGIX & $\mathbf{0 . 5 3 3}$ & $\mathbf{5 . 4 7 1}$ & $\mathbf{9}$ \\
29 & MAFGX & $\mathbf{1 . 8 4 9}$ & $\mathbf{2 0 . 4 9 0}$ & $\mathbf{1 0}$ \\
\hline
\end{tabular}

TABLE 8: Selecting the best assets for making portfolio for $\alpha \leq 0.4$.

\begin{tabular}{lcccc}
\hline & & Expected return & Variance & Ranking \\
\hline 48 & UMBIX & 1.833 & 12.379 & 1 \\
54 & FMAGX & 1.681 & 14.225 & 2 \\
34 & MDFGX & 1.942 & 18.833 & 3 \\
32 & MCOBX & 1.959 & 19.729 & 4 \\
33 & MCOFX & 1.875 & 18.821 & 5 \\
27 & JAWWX & $\mathbf{1 . 9 4 6}$ & $\mathbf{2 0 . 7 0 5}$ & $\mathbf{6}$ \\
30 & MBFGX & $\mathbf{1 . 9 2 3}$ & $\mathbf{2 0 . 6 2 6}$ & $\mathbf{7}$ \\
29 & MAFGX & $\mathbf{1 . 8 4 9}$ & $\mathbf{2 0 . 4 9 0}$ & $\mathbf{8}$ \\
16 & FIUIX & $\mathbf{1 . 3 9 8}$ & $\mathbf{1 3 . 8 1 3}$ & $\mathbf{9}$ \\
52 & WAGEX & $\mathbf{1 . 6 2 5}$ & $\mathbf{1 7 . 6 1 9}$ & $\mathbf{1 0}$ \\
\hline
\end{tabular}

to be more influenced, it should be used of orness $>0.5$. Thus, if investor wants peer-evaluated to be more influenced, it should be used of orness $<0.5$. In Tables 7 and 8, rankings have been designated for ten of the best mutual funds via OWA operator weights in cross-efficiency evaluation. Since there are a large number of assets to invest in, this objective leads to two investment problems. First, the assets are selected for making portfolio and, second, the proportion or weights are determined to be allocated to the selected assets. Selection of assets to be included in portfolio is followed by using crossefficiency evaluation. Model (13) is used for this purpose. In this regard, this model is used to analyze the given 57 mutual funds and ten of the best mutual funds are obtained. The other methods of ranking can be used for ten of the best mutual funds for asset allocation in the future.

\section{Conflict of Interests}

The authors declare that there is no conflict of interests regarding the publication of this paper.

\section{Acknowledgment}

The authors' sincere thanks go to the known and unknown friends and reviewers who meticulously covered the paper and provided them with valuable insights.

\section{References}

[1] H. M. Markowitz, "Portfolio selection," Journal of Finance, vol. 7, pp. 77-91, 1957.

[2] W. F. Sharpe, "Capital asset prices: a theory of market equilibrium under conditions of risk," Journal of Finance, vol. 19, pp. 425-442, 1964.

[3] A. Charnes, W. W. Cooper, and E. Rhodes, "Measuring the efficiency of decision making units," European Journal of Operational Research, vol. 2, no. 6, pp. 429-444, 1978.

[4] M. R. Morey and R. C. Morey, "Mutual fund performance appraisals: a multi-horizon perspective with endogenous benchmarking," Omega, vol. 27, no. 2, pp. 241-258, 1999.

[5] T. Joro and P. Na, "Portfolio performance evaluation in a meanvariance-skewness framework," European Journal of Operational Research, vol. 175, no. 1, pp. 446-461, 2006.

[6] T. R. Sexton, R. H. Silkman, and A. J. Hogan, "Data envelopment analysis: critique and extensions," in Measuring Efficiency: An Assessment of Data Envelopment Analysis, R. H. Silkman, Ed., pp. 73-105, Jossey-Bass, San Francisco, Calif, USA, 1986.

[7] R. H. Green, J. R. Doyle, and W. D. Cook, "Preference voting and project ranking using DEA and cross-evaluation," European Journal of Operational Research, vol. 90, no. 3, pp. 461-472, 1996. 
[8] J. Wu, L. Liang, and Y. C. Zha, "Preference voting and ranking using DEA game cross efficiency model," Journal of the Operations Research Society of Japan, vol. 52, no. 2, pp. 105-111, 2009.

[9] W.-M. Lu and S.-F. Lo, "A closer look at the economicenvironmental disparities for regional development in China," European Journal of Operational Research, vol. 183, no. 2, pp. 882-894, 2007.

[10] W.-M. Lu and S.-F. Lo, "A benchmark-learning roadmap for regional sustainable development in China," Journal of the Operational Research Society, vol. 58, no. 7, pp. 841-849, 2007.

[11] J. Wu, L. Liang, D. Wu, and F. Yang, "Olympics ranking and benchmarking based on cross efficiency evaluation method and cluster analysis: the case of Sydney 2000," International Journal of Enterprise Network Management, vol. 2, pp. 377-392, 2008.

[12] J. Wu, L. Liang, and F. Yang, "Achievement and benchmarking of countries at the Summer Olympics using cross efficiency evaluation method," European Journal of Operational Research, vol. 197, no. 2, pp. 722-730, 2009.

[13] J. Wu, L. Liang, and Y. Chen, "DEA game cross-efficiency approach to Olympic rankings," Omega, vol. 37, no. 4, pp. 909918, 2009.

[14] J. Doyle and R. Green, "Efficiency and cross-efficiency in DEA: derivations, meanings and uses," Journal of the Operational Research Society, vol. 45, no. 5, pp. 567-578, 1994.

[15] J. R. Doyle and R. H. Green, "Cross-evaluation in DEA: improving discrimination among DMUs," INFOR, vol. 33, pp. 205-222, 1995.

[16] L. Liang, J. Wu, W. D. Cook, and J. Zhu, "The DEA game crossefficiency model and its nash equilibrium," Operations Research, vol. 56, no. 5, pp. 1278-1288, 2008.

[17] Y.-M. Wang and K.-S. Chin, "The use of OWA operator weights for cross-efficiency aggregation,” Omega, vol. 39, no. 5, pp. 493503, 2011.

[18] Y.-M. Wang and C. Parkan, "A minimax disparity approach for obtaining OWA operator weights," Information Sciences, vol. 175, no. 1-2, pp. 20-29, 2005.

[19] W. F. Sharpe, "Investment," in Envelopment Analysis, Management Science, vol. 30, pp. 1078-1092, Prentice-Hall, 3rd edition, 1985.

[20] A. Charnes, W. W. Cooper, A. Y. Lewin, and L. M. Seiford, Eds., Data Envelopment Analysis: Theory, Methodology and Applications, Kluwer Academic Publishers, Boston, Mass, USA, 1994.

[21] R. R. Yager, "On ordered weighted averaging aggregation operators in multi-criteria decision making," IEEE Transactions on Systems, Man and Cybernetics, vol. 18, no. 1, pp. 183-190, 1988.

[22] M. O’Hagan, “Aggregating template or rule antecedents in realtime expert systems with fuzzy set logic," in Proceedings of the 22nd Annual IEEE Asilomar Conference on Signals, Systems and Computers, pp. 681-689, Pacific Grove, Calif, USA, 1988.

[23] R. D. Banker, A. Charnes, and W. W. Cooper, "Some models for estimating technical and scale inefficiencies in data envelopment analysis," Management Science, vol. 30, no. 9, pp. 10781092, 1984.

[24] W. D. Cook, L. Liang, and J. Zhu, "Measuring performance of two-stage network structures by DEA: a review and future perspective," Omega, vol. 38, no. 6, pp. 423-430, 2010.

[25] J. C. Paradi, S. Rouatt, and H. Zhu, "Two-stage evaluation of bank branch efficiency using data envelopment analysis," Omega, vol. 39, no. 1, pp. 99-109, 2011.
[26] C. Kao, "Malmquist productivity index based on commonweights DEA: the case of Taiwan forests after reorganization," Omega, vol. 38, no. 6, pp. 484-491, 2010.

[27] H. Chang, H. L. Choy, W. W. Cooper, and T. W. Ruefli, "Using Malmquist Indexes to measure changes in the productivity and efficiency of US accounting firms before and after the SarbanesOxley Act," Omega, vol. 37, no. 5, pp. 951-960, 2009.

[28] F. Fiordelisi and P. Molyneux, "Total factor productivity and shareholder returns in banking," Omega, vol. 38, no. 5, pp. 241253, 2010.

[29] M. Asmild, J. C. Paradi, and J. T. Pastor, "Centralized resource allocation BCC models,” Omega, vol. 37, no. 1, pp. 40-49, 2009. 


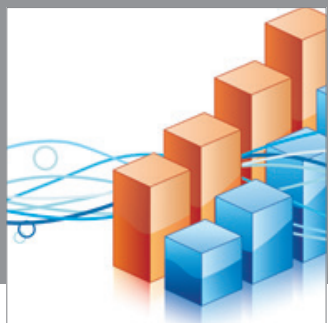

Advances in

Operations Research

mansans

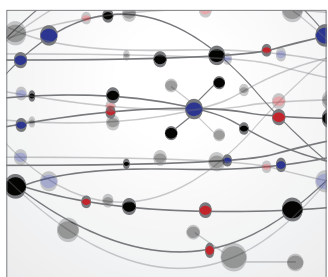

The Scientific World Journal
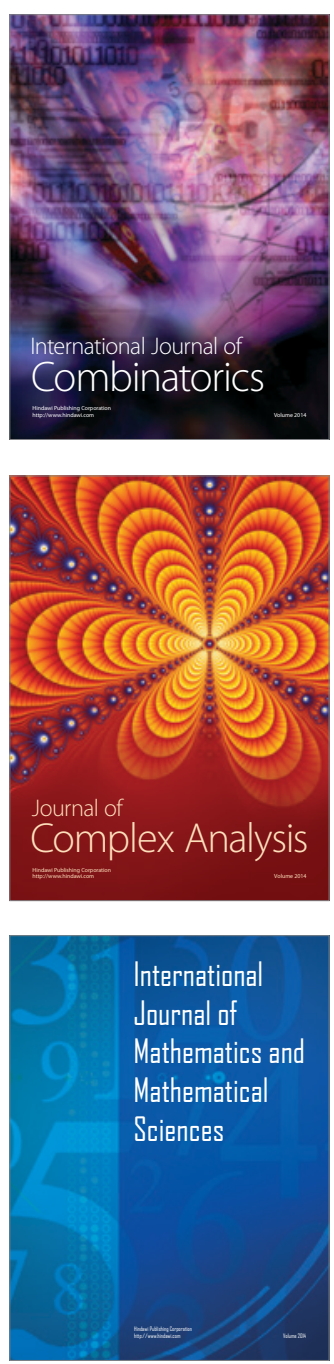
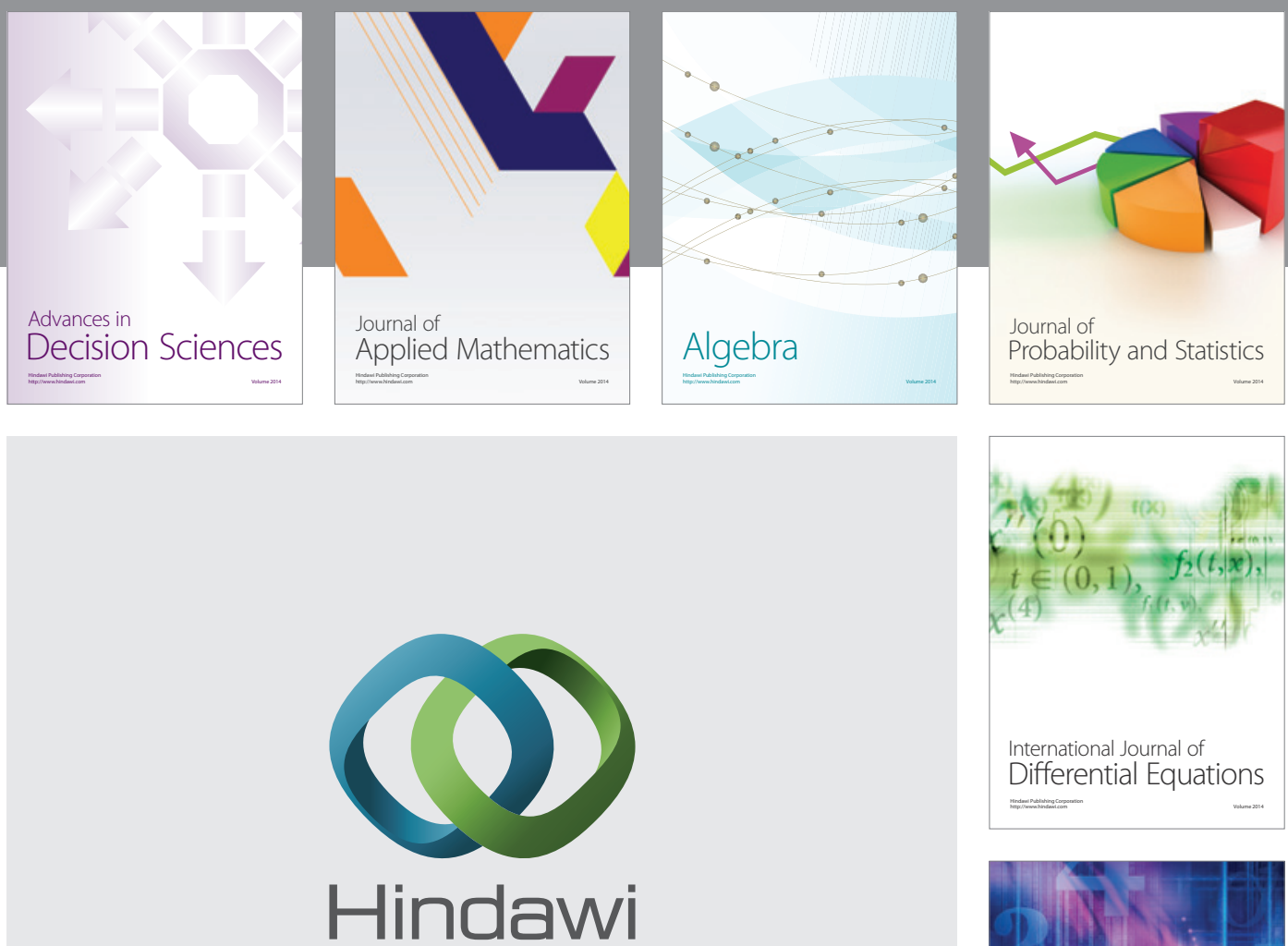

Submit your manuscripts at http://www.hindawi.com
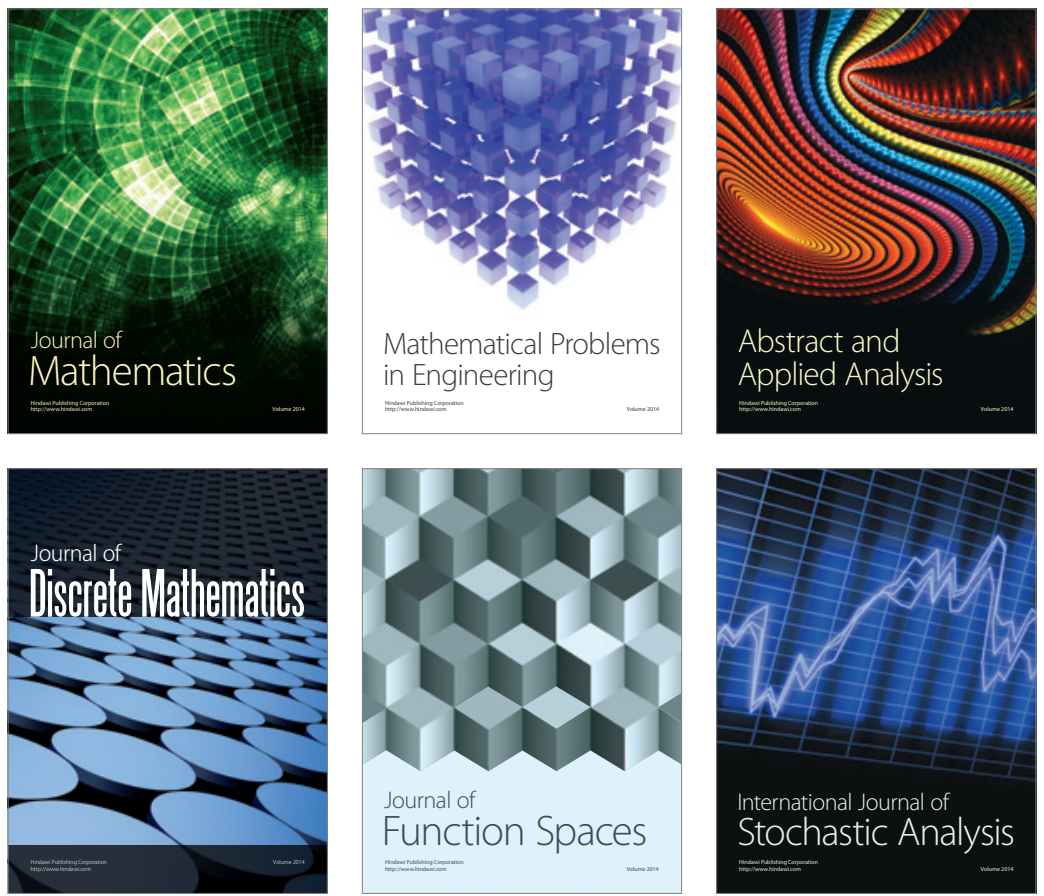

Journal of

Function Spaces

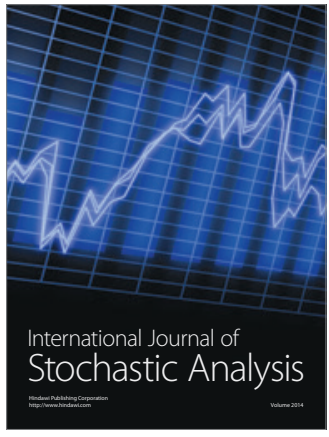

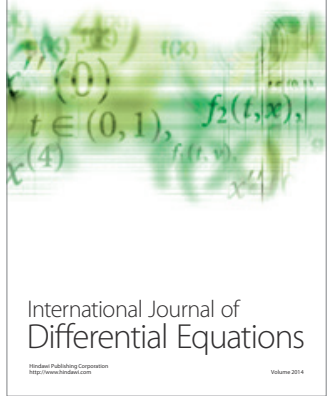
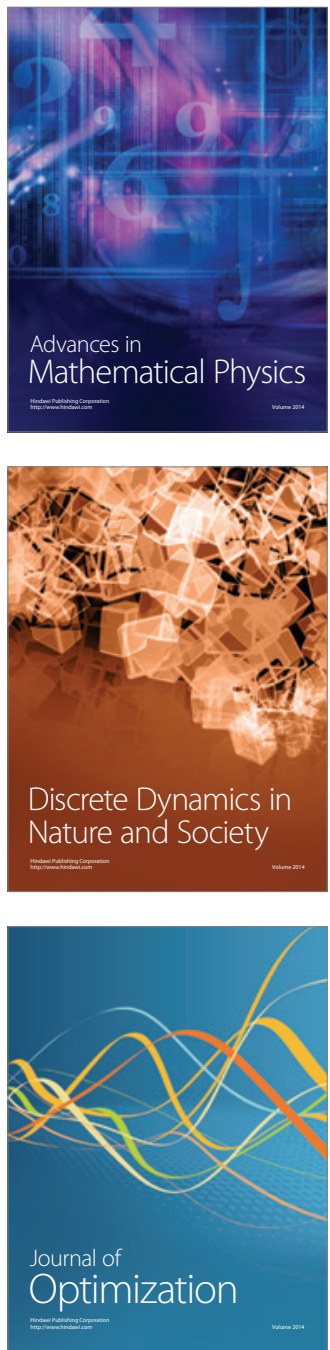